\title{
Article \\ Demonstration of a Novel Alternating Current Hybrid Concept for a Fuel Cell-Battery Hybrid Electric Aircraft
}

\author{
Debjani Ghosh (D, Caroline Willich*(D), Christiane Bauer (D) and Josef Kallo
}

Citation: Ghosh, D.; Willich, C.;

Bauer, C.; Kallo, J. Demonstration of a Novel Alternating Current Hybrid Concept for a Fuel Cell-Battery Hybrid Electric Aircraft. Energies 2021, 14, 7350. https://doi.org/ $10.3390 /$ en 14217350

Academic Editors: Felix Barreras and Mario Marchesoni

Received: 12 August 2021

Accepted: 1 November 2021

Published: 4 November 2021

Publisher's Note: MDPI stays neutral with regard to jurisdictional claims in published maps and institutional affiliations.

Copyright: (c) 2021 by the authors. Licensee MDPI, Basel, Switzerland. This article is an open access article distributed under the terms and conditions of the Creative Commons Attribution (CC BY) license (https:/ / creativecommons.org/licenses/by/ $4.0 /)$.
Institute for Energy Conversion and Storage, Ulm University, Albert-Einstein-Allee 47, 89081 Ulm, Germany; debjani.ghosh@uni-ulm.de (D.G.); christiane.bauer@uni-ulm.de (C.B.); josef.kallo@uni-ulm.de (J.K.)

* Correspondence: caroline.willich@uni-ulm.de

\begin{abstract}
Hybrid electric aircraft offer the potential to decrease emissions from air travel. A new hybrid concept is proposed for a fuel cell-battery hybrid aircraft. In contrast to existing hybrids, the proposed concept puts a battery directly on the AC phases of the motor, which together with a suitable switching circuit superimposes the DC voltage from the battery on the AC voltage of the motor phase providing a voltage boost depending on the battery voltage, which can be used during a high-power demand flight phase. The system is also capable of recharging the battery during flight. The necessary switching architecture was developed and modeled in MATLAB/Simulink to verify the concept and an experimental setup was built for demonstrating the functionality. Simulation and experimental results showed a very good agreement which is very promising for the proposed new hybrid topology.
\end{abstract}

Keywords: hybrid system; battery; fuel cell; electric aircraft; power control

\section{Introduction}

The threat of adverse climate change is becoming a prominent issue day by day. Emissions from the burning of fossil fuels in the transportation sector is one of the main contributors to the problem [1]. $\mathrm{CO}_{2}$ is the largest emission component in the aviation sector, comprising $70 \%$ of the exhaust [2]. Emissions from the aviation sector also include other pollutants and greenhouse gases, making this sector one of the top 10 global emitters [3]. Although technological advances have made it possible to reduce the amount of fuel burned and emissions produced per passenger, a continued growth in air traffic outweighs the improvement. The International Civil Aviation Organization (ICAO) predicts that the international aircraft emissions can become three times higher by 2050 compared to 2015 [4]. The European Green Deal aims to achieve a 90\% decrease of transportation emissions by 2050, which includes emissions from aviation sector as well [5]. Therefore, it is important to develop new technologies for aviation that will be environment friendly and help to transit from fossil fuels to green energy sources. Hybrid electric aircraft based on fuel cells (FCs) as primary energy source and batteries are a promising technology and will help to reduce $\mathrm{CO}_{2}$ emission. Several such systems have already been tested successfully [6-8].

Fuel cells generate electrical power without harmful emissions and the products are only water and waste heat [9]. They also have higher efficiencies ( $>50 \%)$ than an internal combustion engine [10] and, in comparison to batteries, they offer the advantages of high energy densities meaning they are better suited as energy source for medium and long distance flights. Nevertheless, fuel cells have a slow dynamic response and for flight phases with high power demand, combining a fuel cell with a battery can result in an improved performance [11,12]. As determined by Lijun Gao et al., the peak power with a fuel cellbattery hybrid can be four times higher than the power fuel cell can provide alone [13] Use of the battery as a secondary source provides a power boost when the load demand is higher, such as start or take-off. Like this, the advantage of the high-energy density of fuel cells and the high-power density of batteries are combined. There are several existing 
topologies for a fuel cell-battery hybrid system. These conventional hybrid systems usually connect the fuel cell and the battery in parallel connection in the DC side of the inverter.

In an active hybrid system one or more DC/DC converters are used between the fuel cell and the battery as shown in Figure 1a. In this configuration, the DC/DC converter actively controls the fuel cell and the battery to regulate the load sharing [13] and both sources can be operated in such a way that they generate to produce maximum power simultaneously. The peak power supply capability of an active hybrid is much higher than passive topology. However, this active hybrid topology has additional power losses and weight due to the DC/DC converter. According to literature, the DC/DC converter can be $3.2-65 \mathrm{~kg}$ for a system of approximately $100 \mathrm{~kW}$ range of peak load power demand [14-16].

a)

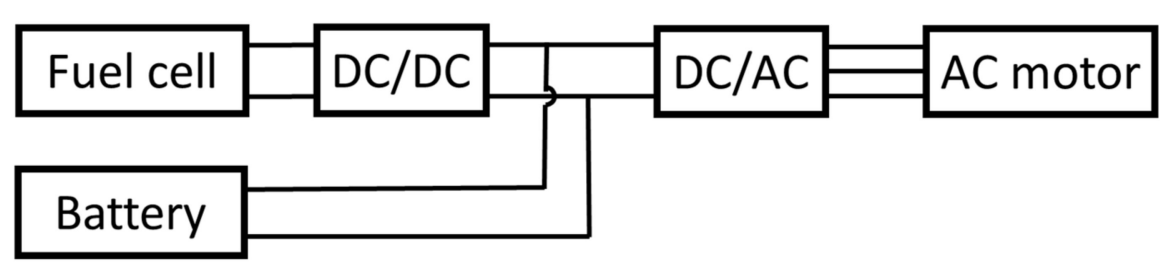

b)

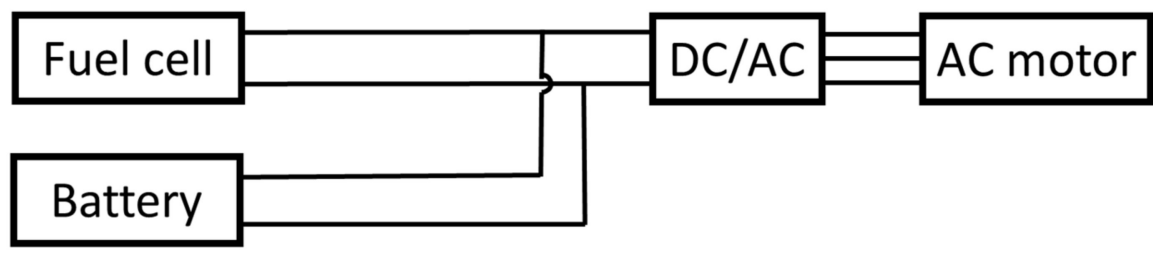

Figure 1. Active (a) and passive (b) fuel cell battery topology in conventional hybrid systems.

There are also existing hybrids with a passive topology as shown in Figure 1b. Here, the fuel cell and the battery are directly connected to the DC link side without any additional converters [17]. The passive topology has less power loss and cost due to the absence of DC/DC converter. Nevertheless, it needs proper coordination of the voltage-current behavior between the battery and the fuel cell and in this type of hybrid, fuel cell nominal voltage determines the battery pack design. There are also variations on the described topologies. For example, the HY4 aircraft uses a variation of a direct system with additional diodes and a separate path for recharging the battery [18,19].

This paper proposes and describes a novel hybrid concept for a fuel cell-battery drivetrain, which does not connect the fuel cell and battery in parallel on the DC side of the inverter as described above. Instead, it places three batteries directly onto the three phases of the electric motor as shown in Figure 2a. The motor phases are supplied from the inverter with AC voltage, but the batteries can only provide DC voltage. Therefore, a suitable switching circuit was developed and tested to superimpose the battery DC voltage on top of the AC voltage of the motor during each AC phase. This new hybrid configuration, with the newly developed switching circuit, makes it possible to increase the voltage on the electric motor by adding the voltage of the battery on top of the AC voltage provided by the inverter of the electric motor during each AC phase. The resulting power increase can then be used during take-off or climb if the fuel cell alone is not able to achieve the bigger load demand. The new concept excludes the necessity of a DC/DC converter between the fuel cell and the battery as found in the existing active hybrid topology while still allowing a complete control of both the fuel cell and the battery and there are no constraints regarding the voltage matching between fuel cell and battery as in the traditional passive hybrid described above. Another advantage of the newly proposed concept is that between the DC link and the AC side an inverter with a smaller power rating and lower weight can be used compared to the conventional hybrids described 
above since only the fuel cell voltage has to be converted by the inverter and not the battery voltage as well. The energy management between the two sources, fuel cell and battery, is crucial for an efficient operation of the hybrid drivetrain. The energy management strategy distributes the power demand of the aircraft between different power sources in such a way that each power source can be utilized optimally. There have been different techniques developed over the years for a good energy management strategy, using for example a fuzzy logic approach [20], battery involved energy managements with Deep Deterministic Policy Gradient Algorithm [21] or Soft Actor-Critic DRL Algorithm [22]. For the aircraft HY4, a Power Management Control and Delivery (PMCD) unit [19] is used to manage the power demand and control the power for different flight phases while additionally providing redundancy and more safety for the aircraft operation. In this paper, it is assumed that an existing energy management system is available on the on-board computer which will send the command to the battery unit of the AC hybrid to turn on and off as required by the mission profile.

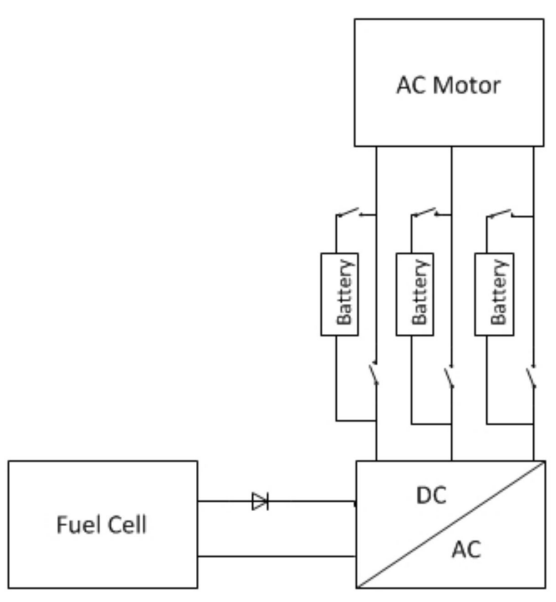

(a)

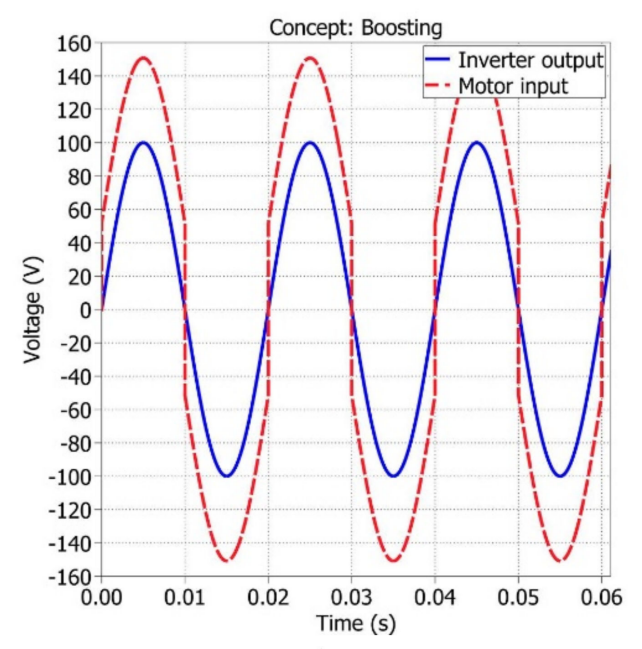

(b)

Figure 2. AC hybrid concept [23]. (a) AC hybrid topology. (b) Voltage boosting by AC hybrid.

\section{Description of the Proposed AC Hybrid Concept}

In the newly proposed AC hybrid concept, batteries are directly connected to the motor on each phase (Figure 2a). This configuration will superimpose the DC voltage from the battery on the $\mathrm{AC}$ voltage of the motor, which will provide a voltage increase directly on the motor phases, resulting in a motor voltage boost. A suitable switching circuit is required to correctly superimpose the $\mathrm{DC}$ voltage onto the $\mathrm{AC}$ voltage as illustrated in Figure $2 \mathrm{~b}$. The switches must be controlled in such a way that a positive DC voltage is applied to the positive half wave of the AC voltage and a negative DC voltage is added during the negative half wave of the $\mathrm{AC}$ voltage. Consequently, there is an increase in the peak-to-peak motor voltage. The precise control of the switching sequence at the correct phase is very important, otherwise a mismatch of the voltage polarity may cause a voltage decrease instead of increase. In Figure 2b, the output voltage of the inverter is $100 \mathrm{~V}$ (in blue). A $50 \mathrm{~V}$ battery is used to superimpose the DC voltage of the battery on top of the inverter AC voltage. The result is $+150 \mathrm{~V}$ in the positive half wave and $-150 \mathrm{~V}$ in the negative half wave. This gives an AC voltage of $150 \mathrm{~V}$ for the motor input, a total rise of $100 \mathrm{~V}$ peak to peak with a $50 \mathrm{~V}$ battery. With the proper switching sequence, the resulting voltage can be increased by twice the battery voltage with this new hybrid concept.

\section{Design Requirement}

The new AC hybrid concept requires an efficient high-speed circuit for connecting the battery. There are three modes of operation for this circuit: 
- Voltage boost mode: The AC power is directed from the inverter to the motor via the battery. The battery is discharging.

- Direct mode: The AC power is routed directly from the inverter to the motor. The battery is disconnected.

- Recharging mode: AC power flows from the motor or from the inverter to the battery and the battery is recharged during flight.

In order to control the switches, a control circuit is also required. The control circuit receives instructions from the pilot interface (Human Machine Interface-HMI) and based on these inputs, selects the suitable mode of operation and switches accordingly. The current, power, speed, torque, etc., must also be constantly monitored to start switching at the right phase angle.

\section{Proposed Architecture of Switching Circuit}

To operate the AC hybrid, a new switching circuit was designed as seen in Figure 3. It consists of four power electronics switches, S1, S2, S3, and S4, forming a bridge architecture. These switches are used in each phase of the motor to connect the battery.

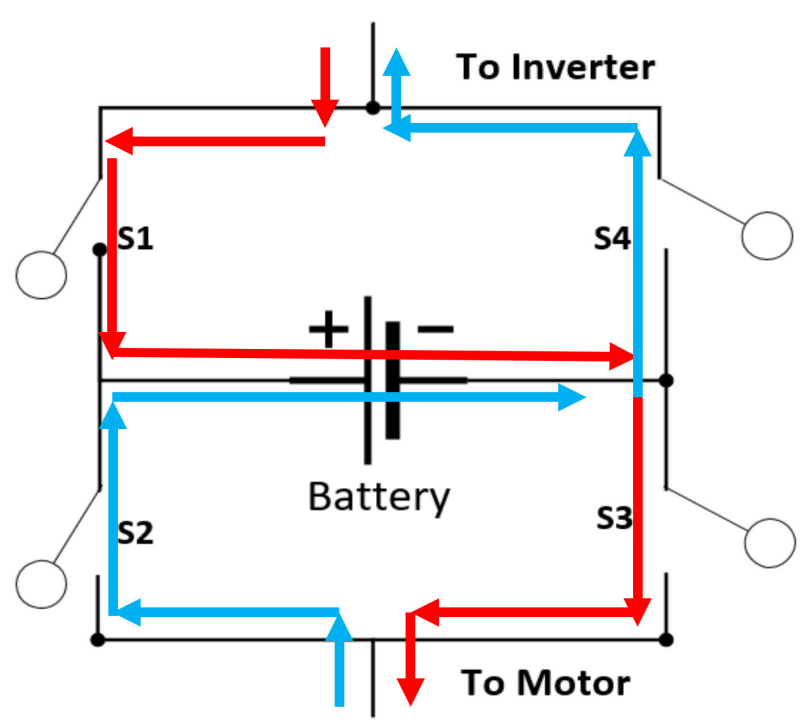

Figure 3. Proposed battery bridge model. Red arrows show positive half cycle switching and blue arrows show negative half cycle switching.

Table 1 shows the necessary switching configuration for the different modes. For example, during the voltage boost mode, switches S1 and S3 will be on during the positive AC half cycle in the motor voltage and current; these two switches will be turned off as soon as a negative half wave starts. Switches S2 and S4 will be turned on during the negative AC half cycle, and uninterrupted power is provided to the motor. Due to this switching arrangement, a unidirectional AC current will flow through the battery.

Table 1. Switching configuration.

\begin{tabular}{clll}
\hline Mode & Positive Half Cycle & \multicolumn{2}{c}{ Negative Half Cycle } \\
\hline Discharging & S1, S3 on, S2, S4 off & S1, S3 off, S2, S4 on \\
\hline Direct (FC only) & S1, S3 off, S2, S4 $\quad$ off & S1, S3 off, S2, S4 off \\
\hline Recharging & S1, S3 off, S2, S4 & on & S1, S3 on, S2, S4 off \\
\hline
\end{tabular}

When the power demand from the motor is low, direct mode can be used in which only the fuel cell is providing power. During this mode, all above mentioned switches are off. 
The recharging mode is used when the motor power demand is very low, so that the fuel cell can supply both the motor and recharge the battery. It can also be used to recuperate energy from the motor to the battery. In this mode, the switching order is the reverse of the discharge mode.

To assure the switching at the correct phase the logic shown in Table 2 is applied, where $V_{\text {battery }}$ is the battery voltage and $V_{\text {motor }}$ and $I_{\text {motor }}$ represent the motor voltage and current, respectively.

Table 2. Logic for the switching of the battery bridge.

\begin{tabular}{ccc}
\hline Mode & Positive Half Cycle & Negative Half Cycle \\
\hline Discharging & $\mathrm{V}_{\text {motor }} \geq 0$ \&\& $\mathrm{I}_{\text {motor }} \geq 0$ & $\mathrm{~V}_{\text {motor }} \leq 0$ \&\& $\mathrm{I}_{\text {motor }} \leq 0$ \\
\hline Recharging & $\mathrm{V}_{\text {motor }} \leq \mathrm{V}_{\text {battery }} \& \& \mathrm{I}_{\text {motor }} \leq 0$ & $\mathrm{~V}_{\text {motor }} \leq-\mathrm{V}_{\text {battery }} \& \& \mathrm{I}_{\text {motor }} \leq 0$ \\
\hline
\end{tabular}

For the discharging mode, zero voltage and current crossing detection is used to determine the positive and negative half cycle. Due to the inductive nature of the load, there is a phase shift between the motor voltage and current and switching for the positive or negative half cycle may only occur when the voltage and current are both positive or negative, otherwise a decrease of the motor voltage due to the mismatch of the polarity during discharge (voltage boost) mode will occur.

The recharging mode is more complex than discharging. In order to avoid an unwanted result of short discharging pulses on the battery it is necessary to insert a short time in which the battery is not charged in each switching cycle. The battery can only be charged when the motor voltage crosses the battery voltage value as the logic in Table 2 shows. This results in a short time delay between the negative and positive half cycles in which the battery is not charged, the length of which depends on the battery voltage. During this short time delay, the system is in direct mode, so that the power supply is uninterrupted.

\section{Simulation Model}

A simulation model was developed in MATLAB Simulink to verify the correct functioning of the AC hybrid concept. Figure 4 shows the simulation model of the drive with a fuel cell, the proposed battery bridge, inverter, and the motor.

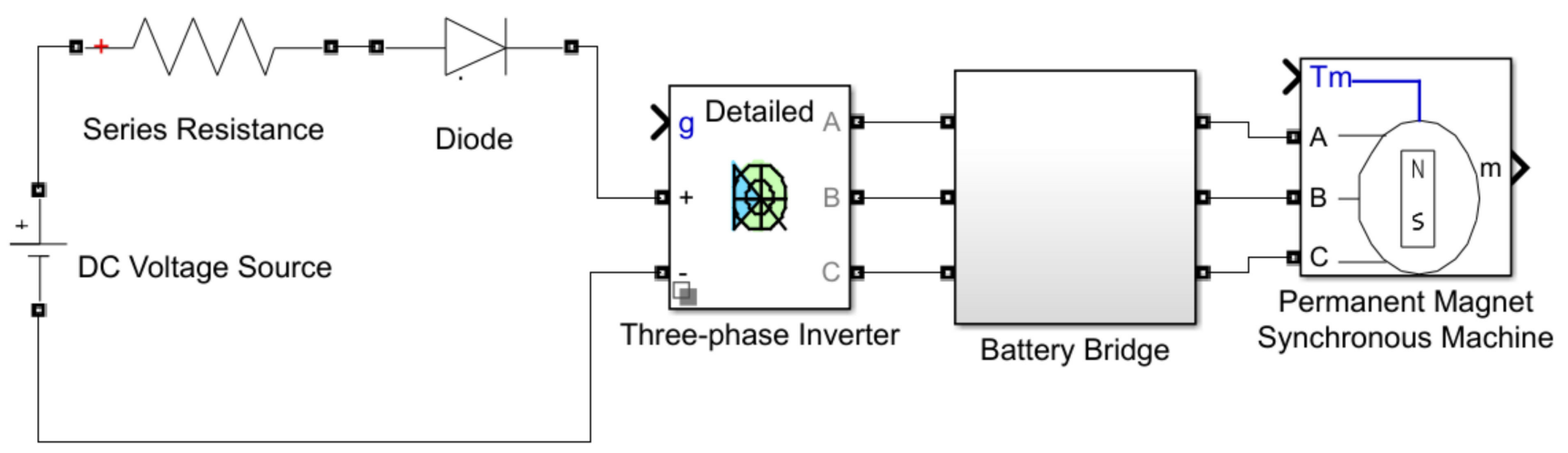

Figure 4. Simplified block diagram of the simulation model.

\subsection{Fuel Cell/DC Source}

The primary power source of the drivetrain is the fuel cell. As the paper focuses on the battery bridge, a $30 \mathrm{~V}$ DC source with a small internal resistance in series from the Simulink library is used for this purpose. This way, it is easier to compare the hardware system as well with simulation results, as the hardware includes a motor supplied directly 
with $30 \mathrm{~V} \mathrm{DC}$ as discussed later. A diode is connected in series to the source to prevent any current flow from inverter towards the source.

\subsection{Inverter and Drive Control}

The drive train has an inverter built with 6 IGBTs. The control for the drive consists of a proportional-integral (PI) controller in the outer control loop. The PI controller is tuned using Ziegler-Nichols method [24], which is a widely used method to tune any proportional (P), proportional-integral (PI), or proportional-integral-derivative (PID) controller. The Ziegler-Nichols method starts by setting the integral and derivative gains to zero and increases the proportional gain until it reaches the point (ultimate gain) when the output of the control loop has stable oscillations. The oscillation period and the ultimate gain value is then used to find out the tuning constant of the controller such as P, PI, or PID values.

The controller compares the setpoint speed with the current speed of the motor and generates a reference torque. The other motor parameters such as hall signals and motor currents are used with this reference torque to generate the switching signal for the gates of the IGBTs in the inverter.

\subsection{Battery Bridge}

Figure 5 shows the switching circuit inside the battery bridge block. A battery is connected to each motor phase with the help of the switching circuit. High speed switches are needed for the circuit as switching is done in each half wave of AC voltage. Hence, four MOSFET switches were selected for the purpose. The gate driver circuit of each MOSFET switch gets the gate signals from the battery bridge controller to enable switching at the correct phase and turn on or off the corresponding MOSFET switches.

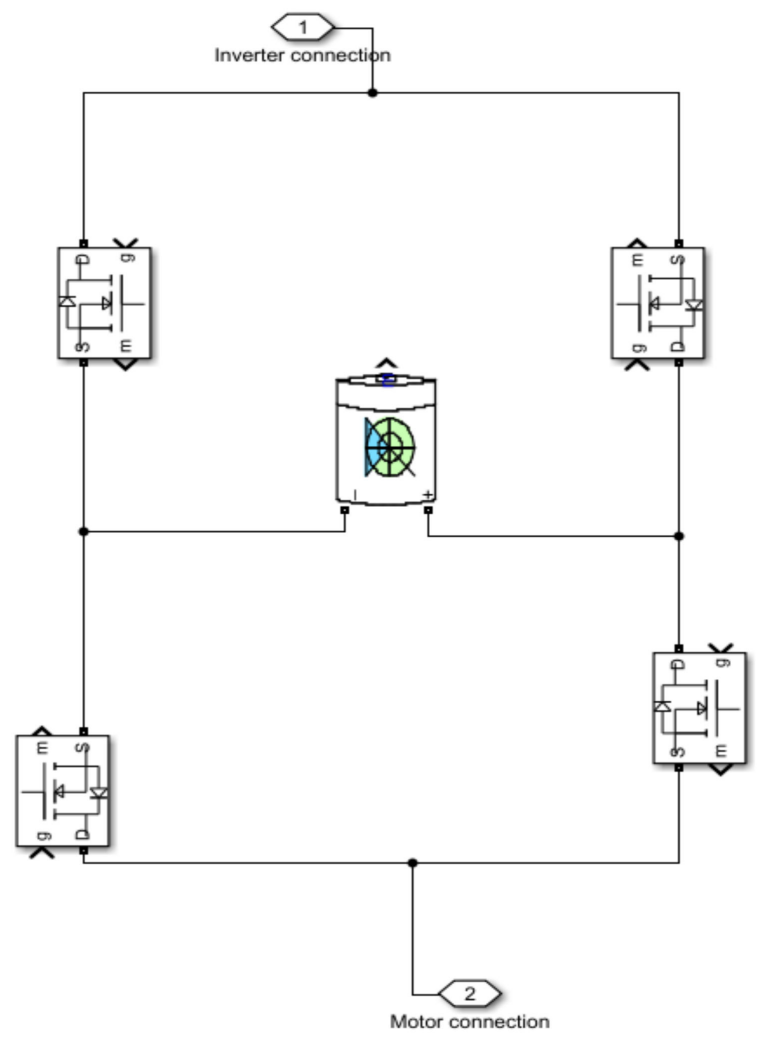

Figure 5. Simulink model of the battery bridge.

The model uses three battery blocks from the MATLAB/Simulink library. This battery block presents a generic dynamic model for various rechargeable batteries such as LeadAcid, Li-ion, NiCd, and Nickel-Metal-Hydride. It is possible to simulate the temperature effect and ageing effect on the battery. 
For the simulation (and for the hardware prototype), two Li-ion rechargeable cells were used in series. There are many types of Li-ion battery models available in literature with different objectives. The electrochemical model contributes to physical cell design and deals with variables such as concentration distribution and galvanostatic charge-discharge. However, this model type is unfit in this context, where only the electrical terminal behavior of the battery is required within a suitable computational time. An electrical equivalent circuit model of a battery is easy to use and suitable for circuit simulations with short computing time. The accuracy of voltage, current characteristics, state of charge, etc., of an electrical model is adequate for this particular application. Therefore, the model used in the simulation is based on an electrical equivalent circuit model of a Li-ion battery with a controlled voltage source and an internal resistance. Table 3 shows the battery parameters for a single Li-ion rechargeable cell from Samsung [25] used in the model and in the hardware.

Table 3. Battery parameters.

\begin{tabular}{cc}
\hline Nominal Voltage $(\mathrm{V})$ & 3.63 \\
\hline Rated capacity $(\mathrm{mAh})$ & $2600(0.2 \mathrm{C}, 2.75$ V discharge $)$ \\
\hline Initial state of charge $(\%)$ & 90 \\
\hline Cut off voltage $(\mathrm{V})$ & 2.75 \\
\hline Maximum discharge current $(\mathrm{mA})$ & 5200 \\
\hline Maximum charge current $(\mathrm{mA})$ & 2600 \\
\hline
\end{tabular}

When the battery current is positive, the battery discharges and when the current is negative, it recharges. In the model it is assumed that both the discharge and recharge characteristics are the same. The model does not consider any self-discharge effect of the battery as this is not relevant for the verification of the concept.

A. Battery bridge controller

The four MOSFET switches in the battery bridge control the power flow through the battery for the different modes. These switches, in turn, are controlled by the battery bridge controller. Figure 6 presents the logical flow chart for the battery bridge controller. It is divided into four types of modes that can be selected by a user or the main computer of the aircraft.

When a particular mode is selected, the logic first checks the SOC of the battery and only then takes the necessary action. For example, if mode 2 (discharge mode) is selected, the controller will first check if the SOC level of the battery is higher or equal to $30 \%$. Only if there is enough energy left in the battery the controller will proceed to zero detection switching according to the logic mentioned in Table 2. If the SOC is between $20 \%$ and $30 \%$, the controller will still perform the switching and send a warning signal to the user that the battery has a low energy level. This helps the user or the pilot to determine a corrective course of action for the flight to avoid using the battery any more than necessary. If the battery has $10-20 \%$ SOC, the controller sends a critical level warning and still performs the switching. If the battery SOC is lower than $10 \%$, the controller refuses to proceed to switching and enters the direct (FC only) mode. It is possible to override this control if a life-threatening situation occurs and the pilot must use the remaining battery energy at all costs. The different SOC levels for the warnings can of course be changed and the controller can be universally adapted according to the application and its requirements. 


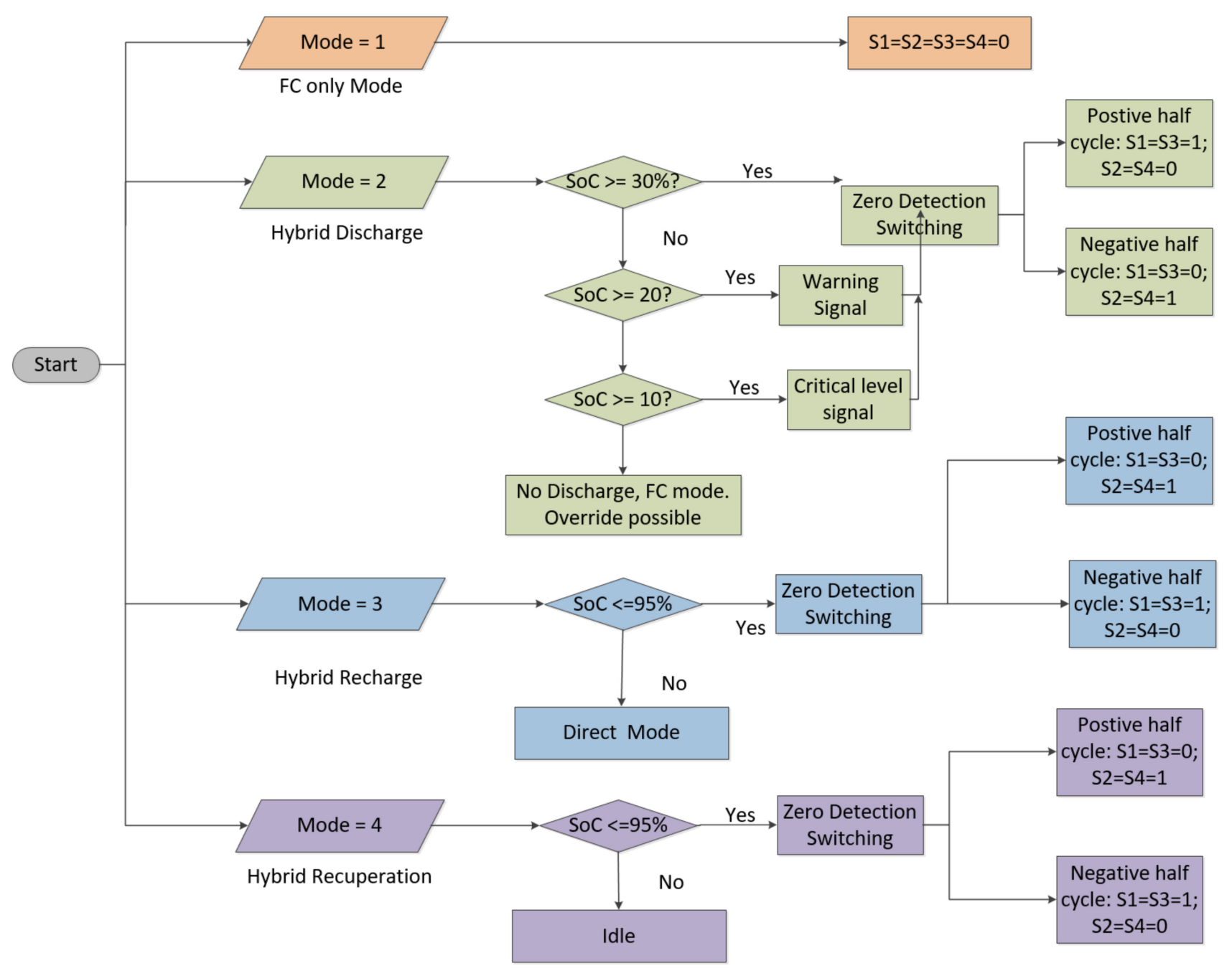

Figure 6. Logical flow chart for the normal operation in different modes of the battery bridge controller.

Similarly, for the recharging and recuperation modes, the controller checks if the battery is already full. It enables charging according to the logic from Table 2 if the SOC level is less or equal to $95 \%$; otherwise, it goes to direct mode (in case of the hybrid recharging mode) or remains idle (recuperation mode).

The use of state machines for energy management is a well-known approach [26,27] and it is useful for reactive and event driven systems. Therefore, the logic chart from Figure 6 where each mode is considered as a state was programed using the MATLAB/Simulink state flow tool.

The model uses a 3-phase BLDC motor (brushless DC motor) from the Simulink library. BLDC motors are like permanent magnet synchronous motors with a trapezoidal back electromotive force (emf). It uses a closed loop speed control using a Hall sensor as mentioned before. The motor can be operated in either generator or motor mode. Therefore, it is possible to simulate the recharge/recuperation mode during flight.

The hardware prototype has a BLDC motor module from Trinamic Motion Control GmbH \& Co which has a QBL5704 motor [28]. Table 4 depicts the parameters used for the simulation of the BLDC motor. 
Table 4. Parameters of a Trinamic BLDC motor.

\begin{tabular}{cc}
\hline Stator Resistance $(\Omega)$ & 0.35 \\
\hline Stator inductance $(\mathrm{mH})$ & 1 \\
\hline Number of pole pairs & 4 \\
\hline Torque constant $(\mathrm{Nm} / \mathrm{A})$ & 0.063 \\
\hline Maximum peak torque $(\mathrm{Nm})$ & 1.3 \\
\hline Rotor inertia $\left(\mathrm{kgm}^{2} \times 10^{-6}\right)$ & 23 \\
\hline
\end{tabular}

\section{Results}

Discharge

A variable speed drive was simulated and Figure 7 shows the simulation results, where the desired starting speed is higher than the system can supply. It can be seen that in the first $30 \mathrm{~s}$ the fuel cell power is not enough to reach the desired speed of $900 \mathrm{RPM}$. Therefore, the system is switched to hybrid discharge mode at $30 \mathrm{~s}$. Immediately after the battery is turned on, the motor phase voltage increases, and the motor is able to achieve the setpoint speed. The drive is switched back to direct mode once the load requirement is decreased during cruise at $200 \mathrm{~s}$. With the supply of $30 \mathrm{~V}$ as fuel cell voltage and $7.2 \mathrm{~V}$ nominal battery voltage, the setup is able to provide $80-100 \mathrm{~W}$ of mechanical power.

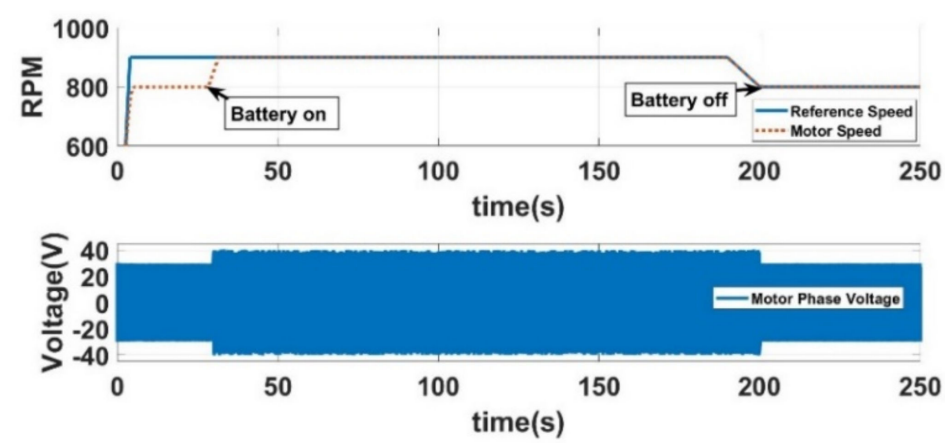

(a)
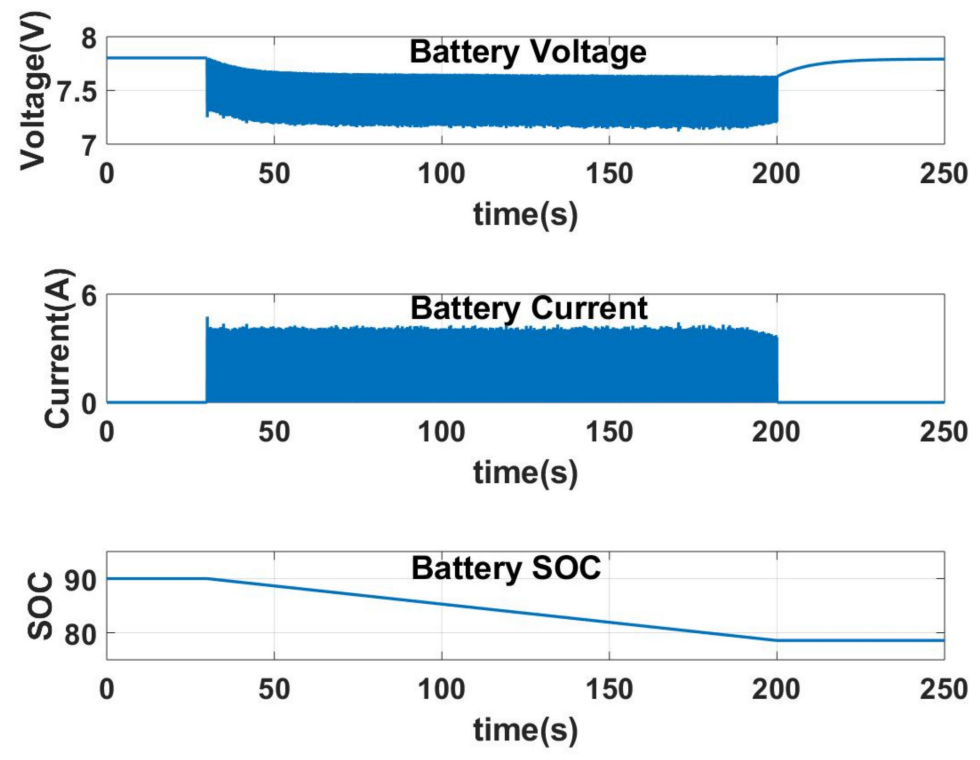

(b)

Figure 7. Simulation results for the battery discharge mode. (a) simulation results; (b) battery parameters. 
The corresponding battery parameters (voltage, current and state of charge) during hybrid mode are also shown in Figure 7 . The battery current acts like a unidirectional alternating current, varying between 0 and $5 \mathrm{~A}$ as expected. The battery voltage also has the shape of a unidirectional AC wave. The decrease of the battery state of charge (SOC) shows the proper discharging of the battery over time.

To better understand the battery current, it is necessary to carefully study the MOSFET current. In Figure 8, it can be seen that switches S1 and S3 carry current during the positive half wave and S2 and S4 during the negative half wave of AC. Thus, the battery only supplies a unidirectional current even though an alternating current flows through the battery bridge circuit.

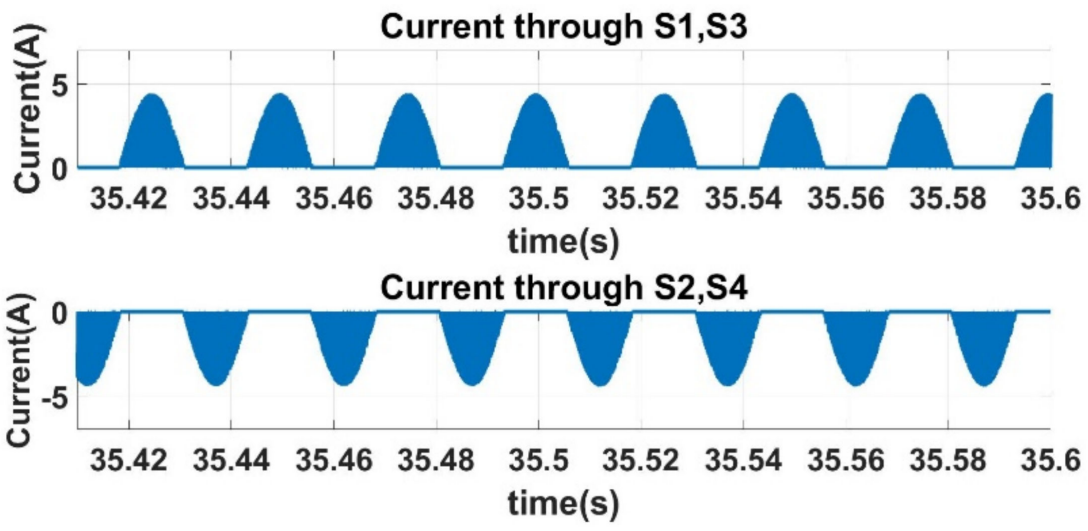

Figure 8. Simulated current through switches S1, S2, S3, and S4 of the battery bridge during discharge.

Figure 9 shows the results of the battery parameters during recharging. The battery recharging follows the switching sequences as described in Table 1. A dead time is required between the switching signals to prevent an unwanted short discharging of the battery. The battery has a negative current during recharging, meaning current is entering the battery. During charging the battery current shows again a unidirectional AC behavior. As expected, the SOC of the battery shows an increment over time, confirming that the battery is getting recharged successfully.
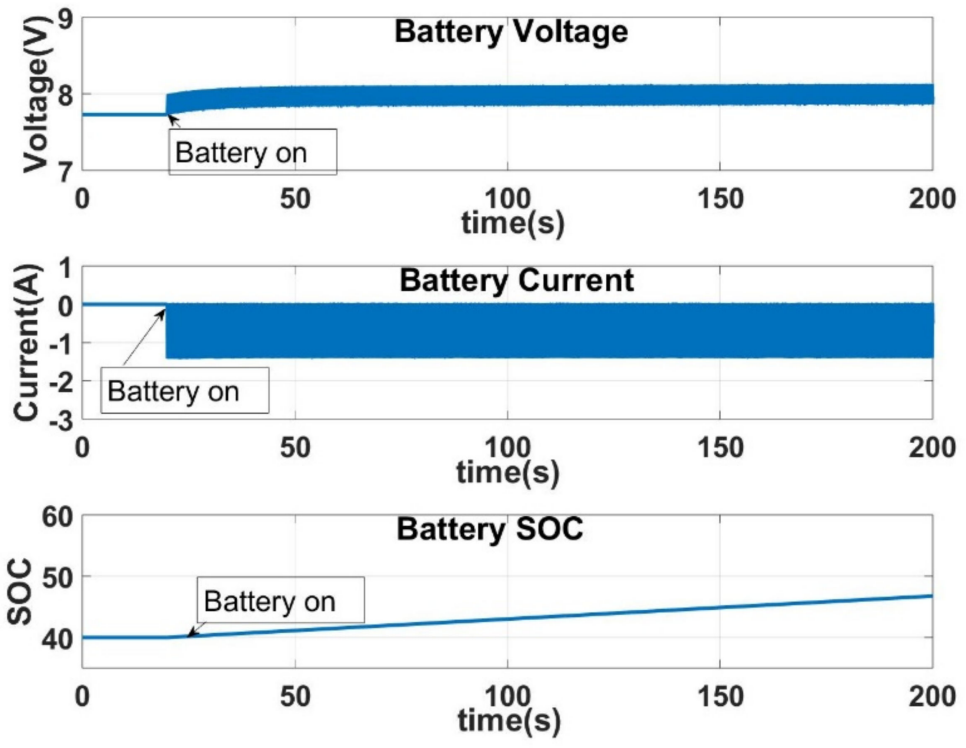

Figure 9. Simulated battery parameters during recharging. 


\section{Hardware Verification}

A small test setup was built to demonstrate the functionality of the concept. The test set up uses a Trinamic BLDC motor along with a 3-phase inverter. For the motor control, a controller board (TMC603A) from Trinamic was used as shown in Figure 10. The board is supplied with 30V DC voltage and has six external n-MOSFETs for the inverter function. The output of the converter is usually connected to the motor phases. To test the AC hybrid, the battery bridge was inserted between the phases of the inverter and the motor as shown in Figure 10. The motor is controlled by the external microcontroller depicted in the picture. Based on the position data of the Hall sensor in the motor, the microcontroller sends pulse width modulation (PWM) signals to the inverter.

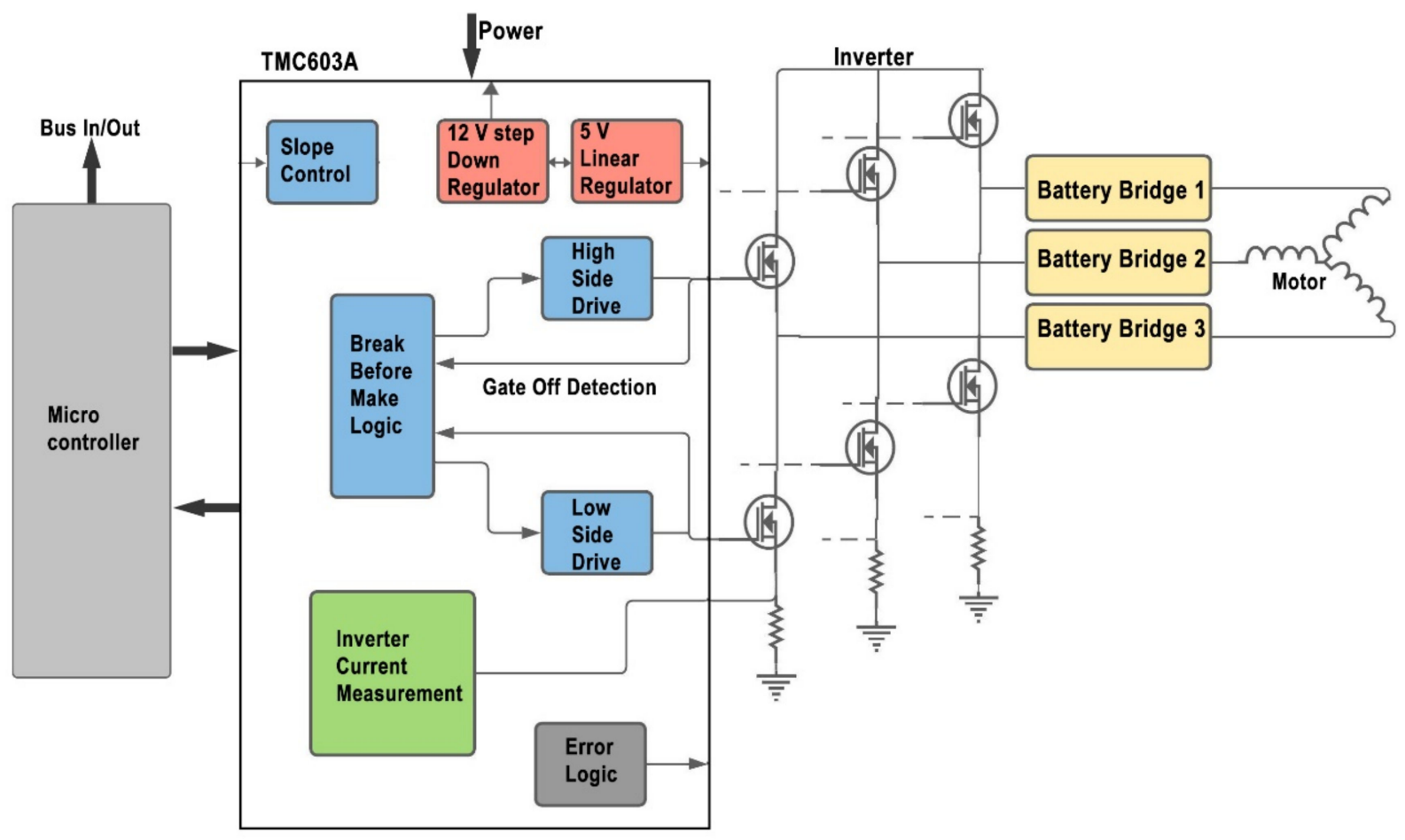

Figure 10. BLDC motor with the controller board and battery bridge.

The control takes place through a cascade regulation of position, speed, and current. The speed controller compares the speed set point with the motor speed measured by the sensors and calculates a set point torque which is converted into a corresponding current in the vector controller and compared with the actual motor phase current. Taking into account the measured position of the motor angle, pulses are then generated for the converter circuit. The microcontroller was programmed using the TMCL-IDE software, provided by Trinamic.

Figure 11 shows the generation concept of the gate signals for the MOSFET switches in the hardware battery bridge. It consists of a logical circuit including sensors, comparators, microcontrollers, optocoupler, resistances, and capacitors. At first, the motor phase voltage and current are measured through sensors. Next, the motor phase current is converted to a voltage signal as the comparator circuit and microcontroller can only use voltage as input for the logical process. A microcontroller (Arduino) is used to synchronously switch the battery bridge for the different operating modes. Depending on the operation modes the microcontroller sends the reference voltage to the comparator for the voltage comparison according to Table 2. In discharging mode, the reference voltage is zero and in recharging or recuperation mode the reference voltage equals the battery voltage. The comparator circuit supplies an input signal to the microcontroller (Arduino) pin every time the voltage of the motor from both positive and negative directions crosses zero voltage or the battery voltage 
for discharging and recharging mode, respectively. It also sends another input signal to the microcontroller every time the motor current crosses zero from either direction. Then, the algorithm shown in Figure 6 is executed in the microcontroller, two complementary PWMs are generated and fed to the gate driver circuit. The gate driver circuit provides the signals to the MOSFETs. Optocouplers are used between the microcontroller and the gate driver circuit to provide the necessary galvanic separation between the power and control circuit.

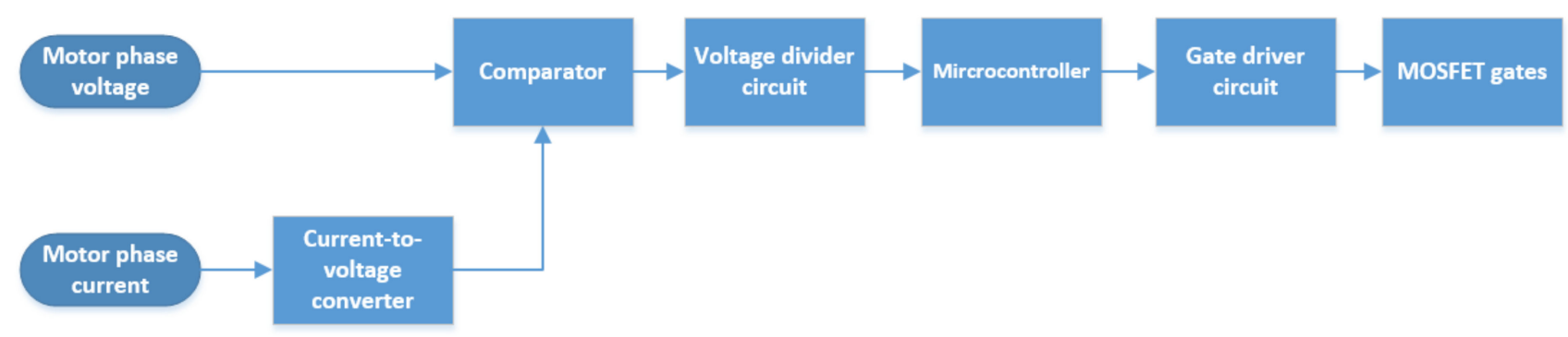

Figure 11. Generation concept of gate signals.

The experiment was performed under ambient lab temperature and pressure. The motor module was mounted on a stable surface and the required motor voltage of $30 \mathrm{~V}$ was ensured. The battery bridge included the same batteries in series as used for the simulation with a nominal voltage of $3.63 \mathrm{~V}$ each. It was ensured that for every motor run, the batteries have the same voltage and SOC.

Figure 12 illustrates the result of switching the battery on and off of the hardware prototype. When the battery bridge is switched on at $37.2 \mathrm{~s}$, the motor speed increases from 800 RPM to about 900 RPM. This matches well with the result obtained from the simulation in Figure 7.

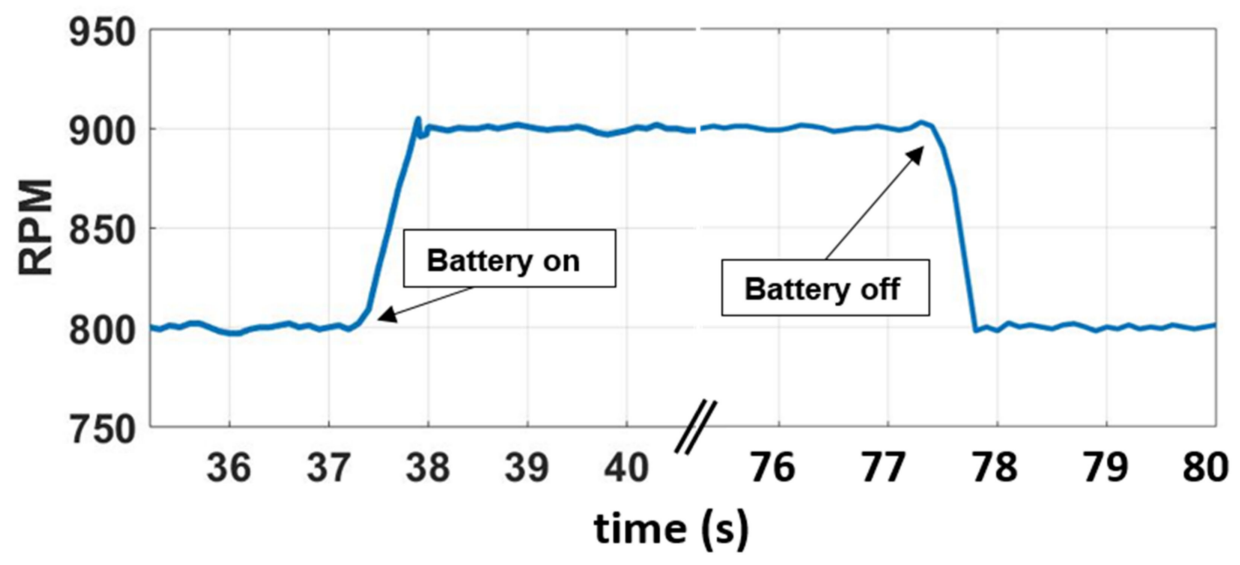

Figure 12. Motor speed with battery discharging.

When the battery is turned off at $77.5 \mathrm{~s}$ it can be observed that the motor speed also decreases indicating a reduction of motor voltage. The motor speed decreases back to 800 RPM which also corresponds well with the simulation results. It can be seen clearly that adding the battery voltage to the motor voltage boosts the motor speed.

Figure 13 shows the measured phase voltage of the Trinamic motor for the battery discharge mode. At $37.2 \mathrm{~s}$, when the battery is turned on, the motor voltage increases to $\pm 36.08 \mathrm{~V}$ and at $77.5 \mathrm{~s}$, it reduces to $29 \mathrm{~V}$ as soon as the battery is disconnected. To validate the simulation data, the simulation was repeated with the same time condition as the experiment. The battery was turned on at $37.2 \mathrm{~s}$ and off at $77.5 \mathrm{~s}$. The motor phase voltage taken as RMS value was used to compare the data between the simulation and the experiment in Figure 13. The motor waveform closely matches the one from the simulation (Figure 7). The difference between the simulation and experimental data is small, 
approximately 1-1.2 $\mathrm{V}$ for the case of the connected battery as well as the disconnected battery. This voltage drop corresponds to the losses that occur mainly in the power electronics components. Furthermore, it can be observed that the peak to peak phase voltage increases two times the battery voltage with some losses as expected from the simulation and the concept of the AC hybrid. Therefore, the hardware measurements prove the functionality of the concept.
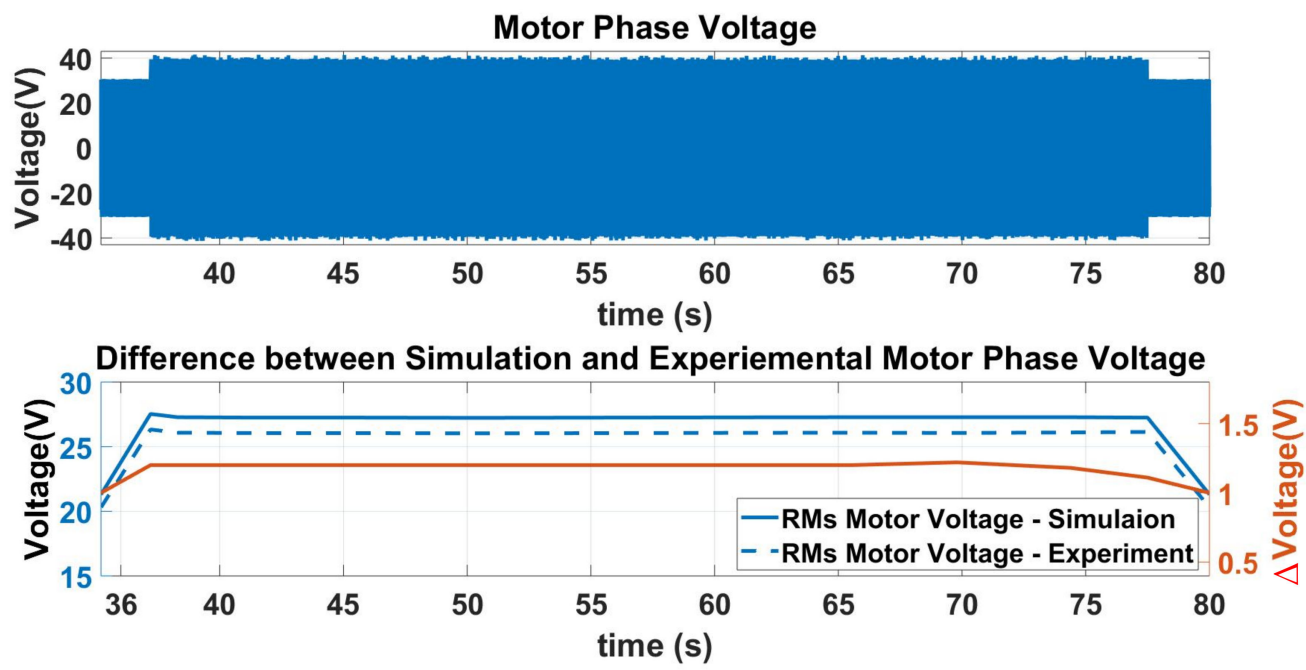

Figure 13. Hardware motor phase voltage and difference between simulation and experimental voltage.

Recharging of the battery was also checked with the hardware system. Figure 14 shows the open circuit voltage (OCV) of a single cell during recharging. It was determined during a cumulative motor run, meaning that the motor ran for few minutes, then the battery was taken out to measure the open circuit voltage. After that, the motor ran again for few minutes and the battery was taken again and OCV was measured. The same was performed several times recording the open circuit voltage of a cell. Since a battery OCV depends on its state of charge, it is evident from Figure 14 that the recharging mode also worked, and the battery was recharged. It can also be seen that for a higher charging current the battery is charged faster than with a lower current.

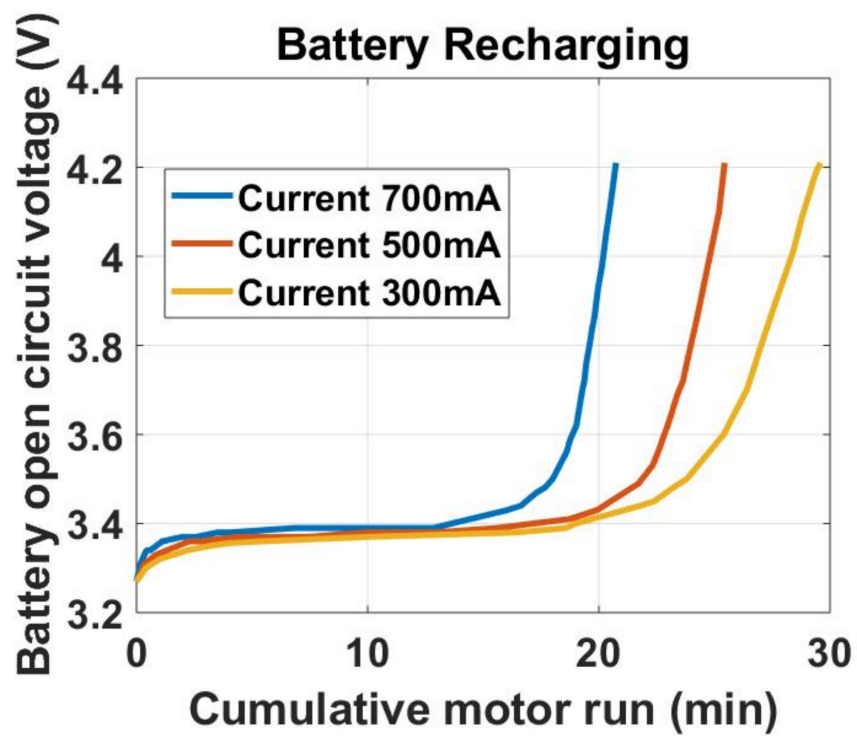

Figure 14. Battery open circuit voltage for one cell during recharging with different charging currents. 


\section{Conclusions}

In the paper, a new AC hybrid topology for a fuel cell battery airplane was developed. In contrast to existing hybrids, the concept places the batteries directly on the phases of the motor. This proposed topology has no need for a DC/DC converter in the drivetrain architecture and at the same time provides the chance to reduce the inverter size. It therefore lowers the total weight of the drivetrain and reduces the power losses. The efficiency of the AC hybrid system is found to be $90 \%$ in simulation whereas a passive hybrid of same power range is $93 \%$. Nevertheless, the AC hybrid provides the decoupling between two sources unlike the passive hybrid system. Therefore, it removes the constraint on the voltage-current matching as in the conventional passive hybrid systems. However, in the AC hybrid the switching must be done very precisely to avoid undesirable outcomes. Without proper synchronizing, the voltage can be decreased instead of increased. This will result in the exact opposite of the required voltage boost. Therefore, the switching of the batteries to each AC phase requires a careful synchronizing.

The necessary switching circuit was modeled and build in hardware and the different operating modes of the system (hybrid, primary energy source only, recharging of the battery via primary energy source, or recuperation) were tested to verify the concept. The results of the simulations as well as the hardware measurements confirm the functionality of the concept and there was a good agreement between the simulation and hardware results. The RPM behavior between simulation and hardware matched exactly, whereas the phase voltage of the motor showed an approximate $4 \%$ deviation that corresponds to the losses in a real circuit. The concept is therefore very promising, but further research and development is needed to scale up and optimize the hardware and assess the benefit the developed AC hybrid offers in comparison with a conventional hybrid in more detail.

Author Contributions: Conceptualization, D.G. and J.K.; Funding acquisition, J.K.; Investigation, D.G.; Methodology, D.G.; Project administration, C.W. and C.B.; Supervision, C.W.; Validation, D.G.; Visualization, D.G.; Writing—original draft, D.G.; Writing—review \& editing, C.W. All authors have read and agreed to the published version of the manuscript.

Funding: This research was funded by the German Federal Ministry of Transport and Digital Infrastructure under the grant 03B10702A and 03B10702A2.

Institutional Review Board Statement: Not applicable.

Informed Consent Statement: Not applicable.

Acknowledgments: The presented work has received funding from the German Federal Ministry of Transport and Digital Infrastructure under the grant 03B10702A and 03B10702A2.

Conflicts of Interest: The authors declare no conflict of interest.

\section{References}

1. Global Greenhouse Gas Emissions Data I Greenhouse Gas (GHG) Emissions I US EPA. Available online: https:/ / www.epa.gov / ghgemissions/global-greenhouse-gas-emissions-data (accessed on 11 May 2021).

2. Fact Sheet | The Growth in Greenhouse Gas Emissions from Commercial Aviation I White Papers I EESI. Available online: https:/ / www.eesi.org/papers/view/fact-sheet-the-growth-in-greenhouse-gas-emissions-from-commercial-aviation (accessed on 11 May 2021).

3. Climate Action Network and International Coalition for Sustainable Aviation joint input to the Talanoa Dialogue-Carbon Market Watch. Available online: https:/ / carbonmarketwatch.org/publications/climate-action-network-and-international-coalitionfor-sustainable-aviation-joint-input-to-the-talanoa-dialogue/ (accessed on 2 November 2021).

4. Trends in Emissions that affect Climate Change. Available online: https://www.icao.int/environmental-protection/Pages/ ClimateChange_Trends.aspx (accessed on 18 June 2021).

5. Reducing emissions from aviation I Climate Action. Available online: https://ec.europa.eu/clima/policies/transport/aviation_ en (accessed on 11 May 2021).

6. DLR. First flight of DLR's HY4 fuel cell light aircraft. Fuel Cells Bull. 2016, 2016, 1. [CrossRef]

7. DLR Press Release. DLR Motor Glider Antares Takes Off in Hamburg-Powered by a Fuel Cell. pp. 2-5. Available online: http:/ / www.dlr.de/en/desktopdefault.aspx/tabid-5105/8598_read-18278/8598_page-2/ (accessed on 2 November 2021). 
8. Koehler, T. Boeing Makes History with Flights of Fuel Cell Demonstrator Airplane. Boeing Frontier. 2008. Available online: https://www.boeing.com/news/frontiers/archive/2008/may/ts_sf04.pdf (accessed on 2 November 2021).

9. Thounthong, P.; Raël, S. The benefits of hybridization: An investigation of fuel cell/battery and fuel cell/supercapacitor hybrid sources for vehicle applications. IEEE Ind. Electron. Mag. 2009, 3, 25-37. [CrossRef]

10. Savvaris, A.; Xie, Y.; Malandrakis, K.; Lopez, M.; Tsourdos, A. Development of a fuel cell hybrid-powered unmanned aerial vehicle. In Proceedings of the 24th Mediterranean Conference on Control and Automation (MED), Athens, Greece, 21-24 June 2016; pp. 1242-1247. [CrossRef]

11. Chan, C.C. The state of the art of electric, hybrid, and fuel cell vehicles. Proc. IEEE 2007, 95, 704-718. [CrossRef]

12. Thounthong, P.; Raël, S.; Davat, B. Energy management of fuel cell/battery/supercapacitor hybrid power source for vehicle applications. J. Power Sources 2009, 193, 376-385. [CrossRef]

13. Gao, L.; Jiang, Z.; Dougal, R. Evaluation of active hybrid fuel cell/battery power sources. IEEE Trans. Aerosp. Electron. Syst. 2005, 41, 346-355. [CrossRef]

14. Fraunhofer. Bidirectional full SiC 200 kW DC-DC Converter for Electric, Hybrid and Fuel Cell Vehicles. 2015. Available online: https:/ / www.iisb.fraunhofer.de/ (accessed on 2 November 2021).

15. Mon, M.M. Design of 50 kW DC-DC Converter used in Hybrid Electric Vehicle. Int. J. Sci. Eng. Technol. Res. 2014, 3, 3368-3373. Available online: https:/ / www.ijsetr.com/ (accessed on 2 November 2021).

16. PowerCell-Give Your Charger the Power it Deserves I SEMIKRON. Available online: https://www.semikron.com/products/ product-lines / air-cooled-igbt-stacks / powercell.html (accessed on 30 September 2021).

17. Bernard, J.; Hofer, M.; Hannesen, U.; Toth, A.; Tsukada, A.; Büchi, F.N.; Dietrich, P. Fuel cell/battery passive hybrid powertrain with active power sharing capability. In Proceedings of the 2010 IEEE Vehicle Power and Propulsion Conference, Lille, France, 1-3 September 2010; pp. 1-5. [CrossRef]

18. Nishizawa, A.; Kallo, J.; Garrot, O.; Weiss-Ungethüm, J. Fuel cell and Li-ion battery direct hybridization system for aircraft applications. J. Power Sources 2013, 222, 294-300. [CrossRef]

19. Hoenicke, P.; Ghosh, D.; Muhandes, A.; Bhattacharya, S.; Bauer, C.; Kallo, J.; Willich, C. Power management control and delivery module for a hybrid electric aircraft using fuel cell and battery. Energy Convers. Manag. 2021, 244, 114445. [CrossRef]

20. Saib, S.; Hamouda, Z.; Marouani, K. Energy management in a fuel cell hybrid electric vehicle using a fuzzy logic approach. In Proceedings of the 2017 5th International Conference on Electrical Engineering-Boumerdes (ICEE-B), Boumerdes, Algeria, 29-31 October 2017; pp. 1-4. [CrossRef]

21. Wu, J.; Wei, Z.; Liu, K.; Quan, Z.; Li, Y. Battery-Involved Energy Management for Hybrid Electric Bus Based on Expert-Assistance Deep Deterministic Policy Gradient Algorithm. IEEE Trans. Veh. Technol. 2020, 69, 12786-12796. [CrossRef]

22. Wu, J.; Wei, Z.; Li, W.; Wang, Y.; Li, Y.; Sauer, D.U. Battery Thermal- and Health-Constrained Energy Management for Hybrid Electric Bus Based on Soft Actor-Critic DRL Algorithm. IEEE Trans. Ind. Inform. 2020, 17, 3751-3761. [CrossRef]

23. Ghosh, D.; Willich, C.; Kallo, J. Development of a novel AC hybrid concept for a fuel cell-battery hybrid electric aircraft with power electronics switches. In Proceedings of the 2018 14th International Conference on Power Electronics (CIEP), Cholula, Mexico, 24-26 October 2018; pp. 105-110. [CrossRef]

24. Widodo, A.B. PID Controllers, 2nd Edition [Åström,_Karl_J.;_Hägglund,_Tore. Available online: https:/ /www.academia.edu/27 771107 /PID_Controllers_2nd_Edition_Åström_Karl_J_Hägglund_Tore_(accessed on 30 September 2021).

25. S. SDI, Specification of product INR18650-25R. 2014. Available online: http://www.datasheet-pdf.com/datasheet/Samsung/79 9163/INR18650-20R.pdf.html (accessed on 2 November 2021).

26. Garcia, P.; Fernández-Ramirez, L.M.; Garcia, C.A.; Jurado, F. Energy Management System of Fuel-Cell-Battery Hybrid Tramway. IEEE Trans. Ind. Electron. 2009, 57, 4013-4023. [CrossRef]

27. Garcia, P.; Fernandez, L.M.; Garcia, C.A.; Jurado, F. Fuel cell-battery hybrid system for transport applications. In Proceedings of the 2009 International Conference on Electrical Machines and Systems, Tokyo, Japan, 15-18 November 2009. [CrossRef]

28. Motion, T.; Gmbh, C. Mot QBL5704 family Manual; 2010. Available online: https:/ /www.trinamic.com/products/drives/bldcmotors-details / qbl5704/ (accessed on 2 November 2021). 